\title{
Interações afetivas na família e na pré-escola
}

\author{
Elza Maria Canhetti Mondin \\ Faculdade de Filosofia, Ciências e Letras de Presidente Venceslau
}

\begin{abstract}
Resumo
A presente pesquisa com crianças pré-escolares enfoca as relações afetivas como elementos indispensáveis à compreensão do crescimento da criança e os papéis da família e da escola nesse empreendimento. Assim, seu objetivo central consistiu na análise das interações afetivas de crianças na família e na pré-escola. Participaram 40 crianças de 4 a 6 anos, matriculadas em uma instituição pré-escolar municipal, localizada no interior do Estado de São Paulo, suas mães e dez professoras. Foram utilizados como instrumentos a observação, o questionário e a entrevista. O primeiro dirigiu-se ao comportamento das crianças no contexto pré-escolar, o segundo ao comportamento das professoras com as crianças e o terceiro destinou-se às mães, cujas verbalizações permitiram constatar as relações interpessoais no ambiente familiar. Os resultados revelaram que as crianças com dificuldades nas relações interpessoais na escola também as apresentavam no ambiente familiar.
\end{abstract}

Palavras-chave: família; crianças; pré-escola; interações afetivas

\begin{abstract}
Affective interactions in family and in pre-school. This research with pre-school children focused affective relations as indispensable elements to understand the growing of a child, and the role of the family and the school in such achievement. Its main goal consisted in the analysis of the affective interactions of children in the family and in pre-school. 40 children (4-6 years old) from a municipal pre-school institution (in the State of São Paulo) took part in the study, as well as their mothers and 10 teachers. Three instruments have been utilized: observation, questionnaire and interview. The first was used to investigate children's behavior in the pre-school context; the second one referred to the teachers' attitude toward the children, and the third one was dedicated to the mothers, whose verbalizations unveiled the personal relationships in the familiar environment. The results revealed that children with personal relationship problems at school, also presented the same problem at home.
\end{abstract}

Keywords: family; children; pre-school; affective interactions

$\mathrm{T}$ oda a fundamentação desta pesquisa baseou-se na busca de conhecimentos resultantes de vasta investigação a respeito do relacionamento da criança nos contextos familiar e pré-escolar.

Foram utilizadas revisões literárias referentes à família, ao apego, e às interações afetivas da criança nos ambientes familiar e pré-escolar. O apego, de acordo com Zamberlan (2002), refere-se ao conjunto de comportamentos que formam uma importante ligação que une uma pessoa a outra. Assim, a responsabilidade materna, conclui a autora, com relação aos cuidados à criança, dirige seus sistemas comportamentais e de apego buscando obter ou manter a proximidade, a interação e a comunicação.

A função do apego no desenvolvimento da personalidade tem sido tema de constantes estudos e vem se aperfeiçoando com métodos de observação mais aprimorados, na tentativa de evidenciar que o papel da simples comunicação entre pais e filhos constitui-se em um determinante do desenvol- vimento emocional. A relação positiva mãe-criança, explica Zamberlan (2002), vem sendo associada à segurança do apego no primeiro ano de vida e na menor freqüência de problemas sócio-emocionais e cognitivos nos anos pré-escolares.

O apego pode ser caracterizado como um conjunto de comportamentos, por meio dos quais o indivíduo inicia ou mantém uma relação afetiva estável com um ou mais indivíduos de seu grupo social (Rossetti-Ferreira, 1986). Sua característica essencial reside na busca de proximidade da pessoa que é objeto de apego. Seu aparecimento ocorre durante o primeiro ano de vida da criança, em especial a partir dos seis meses.

Durante toda a primeira infância permanece de forma intensa, e aos três ou quatro anos, essa intensidade entra em declínio ou sofre modificações em suas formas de expressão. Daí em diante, os comportamentos de apego tornam-se menos evidentes em intensidade e freqüência, todavia persistem durante toda a existência como parte importante do comportamento humano. Dada a influência que o comportamento 
parental tem sobre o comportamento da criança, este estudo inspirou-se em Bowlby (1989), cujos trabalhos revelam que a raiz da personalidade humana está nos primeiros relacionamentos da infância.

Gosselin (2000, p. 105), ao analisar os comportamentos parentais, revê a noção de sensibilidade maternal proposta por Bowlby e Ainsworth, e acrescenta:

Os pesquisadores (Ignjatovic-Savic, Kovac-Cerovic, Plut, \& Pesikan, 1988) sugerem que a sensibilidade maternal abrange ao mesmo tempo respostas às necessidades cognitivas do bebê. Esses autores propõem que o tipo de conforto ofertado pela mãe deve necessariamente abranger um componente cognitivo além de um componente afetivo. Eles dão o exemplo seguinte: um bebê brinca com uma pequena caixa que se abre e fecha; o bebê fecha a caixa e não a pode abrir, então se põe a chorar. Segundo Ainsworth e seus colaboradores (1978), a mãe sensível toma o bebê nos braços e o consola (ela responde com eficácia às necessidades emocionais do bebê). Em contrapartida, para Ignjatovic-Savic e seus colaboradores (1988), a mãe sensível toma o bebê nos braços, consola-o e ensina-o a abrir a caixa (ela responde com eficácia às necessidades emocionais e cognitivas do bebê).

Gosselin (2000) esclarece que as mães de crianças em idade pré-escolar, cuja segurança do apego é elevada, gastam mais tempo com instruções em função das necessidades cognitivas e afetivas das crianças e lhes transferem gradualmente a responsabilidade da supervisão e da execução da tarefa, em comparação às mães de crianças cuja segurança de apego é frágil. Além disso, num contexto de colaboração com adultos estranhos, as crianças cuja segurança de apego é elevada manifestam mais comportamentos pertinentes à tarefa e estratégias metacognitivas, em comparação com crianças cuja segurança do apego não é sólida. O desenvolvimento das habilidades metacognitivas prepara a criança para sair-se bem no domínio escolar. De um lado, elas favorecem o sucesso acadêmico e, de outro, facilitam a associação com seus pares. Assim, é possível supor que a tarefa de proteção não se restringe unicamente a fornecer um contexto adequado a fim de que a criança chegue à plena maturidade física (alimento, abrigo), mas a fazer uso das habilidades metacognitivas. Consiste, também, em ensinar à criança os comportamentos valorizados pela sociedade (comportamentos pró-sociais), permitindo-lhe adaptar-se mais facilmente à vida acadêmica e social. As pesquisas de Rothbaum, Weiz, Pott, Miyake e Morelli (2000) complementam as de Gosselin. Ao explicarem a base segura e a competência, destacam que as crianças consideradas seguras tendem a ser mais autônomas, menos dependentes, mais capazes de desenvolver relacionamentos estáveis com seus pares e menor tendência para terem problemas e, quando os têm, apresentam maior persistência em solucioná-los. Apresentam elevada auto-estima e autoresiliência. Esses autores consideram também a expressividade emocional como um aspecto fundamental para o bem-estar da criança. As pesquisas de Ramires (2003) a respeito das articulações da cognição social e do apego também reforçam a proposta de Gosselin.
Ramires (2003) explica que o processo através do qual a criança desenvolve a sua compreensão do ambiente social e do seu papel nele é complexo e multifacetado: a cognição social abrange mais do que a percepção e as inferências sobre as outras pessoas, envolvendo a compreensão das relações entre os próprios sentimentos, pensamentos e ações, tanto quanto as relações entre esses fatores pessoais e os fatores correspondentes nas outras pessoas. Isso implica que, da perspectiva da cognição social, nossa compreensão da interação social depende de nossa organização dos conceitos sociais e da habilidade de integrar e coordenar perspectivas.

Bowlby (1989) relaciona três modelos básicos de apego: o primeiro refere-se ao apego seguro - a criança dispõe da confiança dos pais. Esta segurança oferece a ela coragem e audácia na exploração do ambiente. Caracteriza-se o referido modelo pela presença constante dos pais, em especial das mães que, sensíveis às necessidades do filho, estão sempre disponíveis em atendê-lo quando busca proteção e conforto. O segundo modelo caracteriza-se pelo apego resistente ou ansioso - a criança não possui a certeza de receber ajuda de seus pais, e por essa razão seu comportamento poderá ser ansioso com relação à separação e inseguro em explorar o mundo. Os pais demonstram disponibilidade em algumas ocasiões, e em outras não. O terceiro modelo diz respeito ao apego com evitação - não há qualquer confiança da criança em ser atendida quando necessita de cuidado ou proteção. A pessoa procura viver sua vida sem a presença do amor ou auxílio de outros. A privação materna refere-se às situações em que a criança não conta com a proteção e afeto maternos. Assim, é possível que a criança, embora convivendo com seus pais, não receba deles, e em especial da mãe, os cuidados e afetos de que necessita.

O tópico seguinte a ser tratado no presente trabalho refere-se à família. É interessante iniciá-lo com as palavras de Winnicott (1997), encontradas no prefácio de Família e o desenvolvimento individual:

Repetidas vezes procurei afirmar e reafirmar a teoria do crescimento emocional da criança, crendo que a estrutura familiar deriva em grande parte das tendências para a organização presentes na personalidade individual. A família possui lugar claramente definido naquele ponto em que a criança em desenvolvimento trava contato com as forças que operam na sociedade. O protótipo desta interação é encontrado na relação original entre crianças e mãe; relação essa em que, por vias extremamente complexas, o mundo representado pela mãe pode vir a auxiliar ou a impedir a tendência inata da criança ao crescimento. (p. IX)

No enfoque de Bowlby (1989), a criança não é um organismo de vida independente e por isso necessita de uma instituição social especial que a auxilie durante o período de imaturidade. Esse auxílio operará de duas formas: primeiramente, ajudando-a a satisfazer suas necessidades orgânicas imediatas, tais como alimentação, calor, abrigo e proteção; em segundo lugar, proporcionando-lhe um ambiente no qual possa desenvolver suas capacidades, sejam físicas, mentais ou sociais, indispensáveis para lidar eficazmente com o seu 
meio físico e social. Para tanto, é necessária uma atmosfera de afeição e segurança. A vida familiar representa, na visão de Goleman (1995), a nossa primeira escola de aprendizado emocional. Nesse espaço íntimo aprendemos como nos sentir em relação a nós mesmos e como os outros vão reagir a nossos sentimentos. Esse aprendizado emocional atua não apenas por meio das ações e comunicações orais, mas também nos modelos que oferecem para lidar com os próprios sentimentos e os que se passam entre marido e esposa. Alguns pais são professores emocionais talentosos, outros são deficientes nessas habilidades. Pesquisas têm demonstrado que a maneira com que os pais tratam seus filhos - seja com rígida disciplina, com compreensão, indiferença ou simpatia - produz conseqüências profundas e duradouras para a vida emocional da criança.

Gottman (1997) define os pais dentro de quatro estilos emocionais. O primeiro refere-se à ignorância total dos sentimentos. A perturbação emocional da criança é considerada como algo trivial ou sem importância e que passa logo. Esse tipo de pais não faz uso dos momentos emocionais para uma aproximação e posterior orientação no campo da competência emocional. O segundo estilo é denominado laissez-faire. Os pais percebem como o filho se sente, mas esperam que ele próprio solucione suas perturbações. Não ensinam ao filho uma resposta emocional alternativa. O terceiro estilo referese à demonstração de desprezo: esses pais são desaprovadores, severos em suas críticas e castigos. Proíbem que seus filhos apresentem reações emocionais. E, finalmente, o quarto estilo envolve os pais orientadores emocionais. Os pais utilizam-se dos momentos emocionais para orientarem seus filhos na busca de alternativas positivas. Não resta dúvida, completa Gottman, de que os pais hoje enfrentam problemas que os do passado não enfrentavam. Uma criança que está sofrendo emocionalmente não deixa os problemas na porta da escola. Conseqüentemente, em todo o país, as escolas vêm acusando um aumento dramático de problemas de comportamento nestas últimas décadas. As escolas estão sendo, essencialmente, uma zona de proteção para uma quantidade cada vez mais crescente de crianças perturbadas pelo divórcio, pobreza e descaso. É preciso ter em mente que a mãe e o pai são a origem de todos os deslocamentos que o indivíduo realiza em direção à independência plena. Assim, a família contribui para a maturidade emocional, permitindo que seus membros se desloquem para famílias mais amplas (agrupamentos maiores) e, ao mesmo tempo, tenham oportunidade de voltarem a ser dependentes a qualquer momento. Esse fenômeno denomina-se segurança. "As crianças vêem na segurança uma espécie de desafio que as convida a provar que podem ser livres” (Winnicott, 1997, p. 43).

O amor materno de que a criança necessita, observa Bowlby (1989), é facilmente encontrado no seio da família e extremamente difícil fora dela. Os serviços habitualmente prestados pelos pais a seus filhos são de tal maneira considerados naturais que a grandiosidade dos mesmos é esquecida. Não há outro tipo de relacionamento no qual um ser humano se coloque de forma irrestrita e contínua à disposição do outro. De acordo com esse enfoque, é interessante analisar os padrões de interação familiar descritos por Bee (1996), que afetam inevitavelmente a segurança da criança. Eles englobam o tom emocional da família, a responsabilidade dos pais em relação à criança, o exercício do controle, a quantidade e a qualidade da comunicação. O primeiro elemento, o tom emocional da família, é de importância básica para a criança. Pais carinhosos se importam com seus filhos, expressam afeição, colocam como prioritárias as necessidades das crianças, respondem de modo empático e sensível aos sentimentos delas. Pais que rejeitam os filhos demonstram claramente por meio de seus comportamentos que não os amam. As lições de empatia têm início na infância com pais que desenvolvem uma sintonia com os sentimentos de suas crianças. As pesquisas registradas em Goleman (1995) constataram que os filhos de pais emocionalmente aptos, comparados aos inaptos, são mais afetivos, sabem lidar com suas próprias emoções, são mais populares e simpáticos, menos rudes e agressivos.

O segundo elemento a ser analisado diz respeito à responsabilidade dos pais em relação à criança. Quando os pais apresentam essa característica, percebem adequadamente os sinais da criança e reagem de modo sensível às suas necessidades.

O exercício do controle constitui-se no terceiro elemento das interações familiares e é possível que a consistência das regras seja um elemento de controle na relação pais e filhos. Essa consistência requer clareza por parte da criança quanto às conseqüências de obedecer ou desobedecer às regras. Alguns pais são muito claros e consistentes, outros se perdem em discussões, ou são vagos em relação ao que é esperado ou tolerado. As condutas parentais mal adaptadas de manejo familiar podem estar correlacionadas a variáveis referidas como perturbadoras e incluem desemprego, violência familiar, conflitos conjugais e divórcio. Zamberlan e BiasoliAlves (1997) explicam que quando os pais participam da vida familiar, estabelecendo divisão de tarefas e rotinas domésticas a todos os seus membros, é provável a aceitação, por parte da criança, da disciplina sem imposições, criando condições para a internalização de valores morais.

É importante lembrar que, além das regras, os comportamentos dos pais são observados e copiados por suas crianças. De acordo com Caballo (2001), as crianças observam como os pais interagem com elas e com as outras pessoas e aprendem seu estilo. Tanto os comportamentos verbais (por exemplo: temas de conversação, fazer perguntas, produzir informações), como os não-verbais (por exemplo: sorrisos, entonação de voz, distância interpessoal) podem ser aprendidos pela modelação durante a infância. Este período, afirma o autor, parece ser responsável em alto grau pelo desenvolvimento futuro. Saldaña, Del Prette e Del Prette (2002) completam as idéias de Caballo:

Na família, por exemplo, o comportamento dos pais torna mais provável o comportamento de filhos, mediante a aprendizagem observacional, formando-se uma cadeia de transmissão de regras de estilos de comportamentos de pais para filhos. (p. 277)

Lohr (2003) explica que os pais constituem o primeiro núcleo social da criança, assim é natural que a figura dos pais e as práticas parentais adotadas tenham grande influência no 
processo de construção das habilidades sociais da criança. Estas habilidades envolvem classes comportamentais como assertividade, solução de problemas e empatia, fundamentais para o convívio entre pessoas. Lubi (2003) informa que o desenvolvimento de habilidades sociais na primeira infância está vinculado intensamente ao ambiente familiar, às vivências e às práticas sociais.

Em contrapartida, o pai restritivo preocupa-se em manter o filho sob seus olhos o tempo todo ou, quando a criança é muito nova, coloca-a em um cercado grande durante parte do dia, para que ela não desorganize a casa. Esse tipo de pai usa habitualmente uma linguagem de caráter imperativo como "venha cá” ou "faça o que eu digo". Provavelmente as regras são substituídas pelo poder e autoridade, e seus filhos possivelmente serão obedientes, pouco agressivos e tímidos, com dificuldades de relacionamento com seus pares (Bee, 1996, p. 375).

É interessante acrescentar a existência de pais permissivos, cujos controles são exercidos de modo insuficiente; seus filhos provavelmente apresentarão uma independência moderada e terão pouca consideração pelos outros. Esses pais, na visão de Gottman (1997), não impõem limites e geralmente não procuram orientar o comportamento das crianças, tampouco as orientam a conhecer suas emoções e a como solucionar seus problemas.

É correto concluir que o processo para atingir o compromisso de desenvolvimento dos filhos requer compreensão e flexibilidade do adulto, e respeito à individualidade da criança. Essas qualidades caracterizam os pais como preparadores emocionais. Para Gottman (1997), esses pais escutam os filhos, demonstrando empatia com palavras tranqüilizadoras, afetuosas, e fazem uso de seu tempo para conversar com a criança triste, irritada ou assustada; sensibilizam-se com seus estados emocionais sem ridicularizá-la, impõem limites e ensinam manifestações aceitáveis de emoção; não sentem que precisam resolver todos os problemas para a criança, entretanto ensinam técnicas para a solução dos mesmos. Conseqüentemente, a criança aprende a confiar em seus sentimentos, regular as próprias emoções e resolver problemas; apresenta auto-estima elevada, facilidade de aprender e de se relacionar com as pessoas.

Aspectos da dinâmica familiar podem ser muito poderosos na vida da criança, visto ser no lar que, em geral, ela desenvolve quase todos os repertórios básicos de seu comportamento, bem como já os tem como funcionais na ocasião em que tem acesso à escola. (Zamberlan \& Biasoli-Alves, 1997, p. 41)

Por fim, resta analisar o último dos padrões de interações: a comunicação. As crianças que cresceram sob a crença de que deveriam ser vistas e não ouvidas apresentam uma grande desvantagem. Privadas de oportunidades de expressar seus sentimentos, opiniões e de confiarem em suas capacidades, muitas dessas crianças acabaram acreditando que não era importante o que tinham a dizer, que elas mesmas não eram importantes, até mesmo que ninguém se importava com elas. A auto-estima delas foi seriamente prejudicada. A capacidade de comunicação apresenta-se sob dois aspectos distintos: ouvir e falar $=$ transmitir. $\mathrm{O}$ primeiro é essencial para o entendimento, para resolver diferenças, para a proximidade e para o amor. O segundo é básico para que os outros saibam o que desejamos ou não, e para satisfazer nossas necessidades. Ouvir, no enfoque de Gottman (1997), significa muito mais do que simplesmente reunir dados por meio da audição. Ouvintes empáticos usam os olhos para detectar sinais físicos das emoções de seus filhos. Usam a imaginação para ver e sentir a situação da perspectiva da criança. Usam as palavras para traduzir de forma tranqüilizadora o conteúdo ouvido e auxiliá-la a nomear as emoções. E, finalmente, usam o coração para sentir verdadeiramente o que a criança está sentindo.

Os bons ouvintes dedicam tempos para ouvir. É uma habilidade importante que pode desenvolver a qualidade da sua vida familiar, seus relacionamentos e a auto-estima de todos. Diz Buscaglia, citado em Hart (1992): "Se vocês encontrarem tempo para conversar todos os dias, jamais se tornarão estranhos” (p. 36).

Antes de passar a considerar as interações entre préescolares e professoras, é preciso enfocar o contexto préescolar conforme algumas revisões literárias atuais. Na educação infantil, destaca-se, de acordo com Gandini e Edwards (2002), a importância de auxiliar as crianças a criarem suas próprias identidades, pertencimento e relacionamento. Ser e fazer parte constituem-se em um elemento da definição de crescimento. Além disso, é preciso oferecer oportunidades para o aprendizado e conhecimentos para as crianças, as famílias e os professores.

De acordo com Vila (2000):

A educação infantil tem três atores: crianças, famílias e profissionais da educação (...) A prática na educação infantil não se pode realizar à margem da família. Por isso a educação infantil (deve ser) uma forma de apoio social para o (melhoramento de) as práticas educativas familiares. (p. 41)

Atualmente, explica esse autor, a educação infantil deve constituir-se em um contexto de desenvolvimento que seja um prolongamento do contexto familiar. Acentua-se a concepção de que a educação pré-escolar vai mais além dos aspectos relacionados à instrução, como a construção de um conjunto de valores, normas e atitudes que permitem à criança conviver bem em seus anos futuros. Para isso, é necessário que a família e a escola mantenham canais de comunicação e relações de confiança mútua e compreensão. New (2002) enfatiza que quando os adultos trabalham juntos para os cuidados com as crianças, não apenas alimentam os seus desenvolvimentos como também enaltecem suas próprias vidas e contribuem com a valorização da comunidade.

Dados empíricos do presente trabalho revelaram que as atividades pré-escolares, envolvendo crianças e professoras, necessitam urgentemente de uma reconfiguração: as professoras precisam saber como escutar as crianças, como permitir que tomem iniciativas e, também, como guiá-las de formas produtivas. Ao prefaciar a obra de Edwards, Gandini e Forman (1999), Gardner faz o seguinte desabafo: 
Como um educador americano, não posso evitar a surpresa por certos paradoxos. Na América, orgulhamo-nos do foco sobre as crianças e, contudo, não prestamos atenção suficiente ao que elas estão realmente expressando. Pedimos a aprendizagem cooperativa entre as crianças e ao mesmo tempo, raramente sustentamos esta cooperação no nível do professor e do administrador. Exigimos trabalhos artísticos, mas raramente conseguimos criar ambientes que possam verdadeiramente apoiá-los e inspirá-los. Pedimos o envolvimento da família, mas detestamos dividir a autoria, a responsabilidade e o crédito com os pais. Reconhecemos a necessidade por uma comunidade, mas com muita freqüência nos cristalizamos imediatamente em grupos com interesses próprios. Saudamos o método da descoberta, mas não temos confiança para permitir que as crianças sigam suas próprias intuições e palpites. Desejamos o debate, mas repetidamente o arruinamos; queremos escutar, mas preferimos falar; somos afluentes, mas não protegemos os recursos que nos permitem permanecer assim e, dessa forma, apoiar a afluência dos outros. (p. XI)

\section{Método}

\section{Participantes}

Tomaram parte no estudo 40 crianças pré-escolares de ambos os sexos, na faixa etária de 4 a 6 anos; suas mães e 10 educadoras, responsáveis pelas turmas. A seleção dessas crianças atendeu ao processo de amostragem aleatória simples, realizado pela diretora da instituição. Suas famílias eram de nível socioeconômico baixo e as educadoras tinham de 10 a 15 anos de experiência no campo da educação infantil.

A escola municipal de educação infantil em que se realizou a coleta de dados atende, gratuitamente, em dois períodos diários, crianças nas idades acima mencionadas e seu quadro profissional envolve uma diretora, uma coordenadora pedagógica, professoras e demais funcionários.

\section{Instrumentos}

Três instrumentos de coleta de dados foram utilizados: observação, questionário e entrevista.

O primeiro, a observação, desenvolveu-se nos meses de fevereiro a abril e os comportamentos observados foram agrupados em um sistema de categorização (9 classes, sendo que 7 delas relacionam-se às atividades pró-sociais e outras 2 relacionam-se às atividades aversivas). Os registros diários foram desenvolvidos através de um protocolo de observação.

$\mathrm{O}$ segundo instrumento, o questionário, foi dirigido às professoras, abordando o relacionamento das crianças com seus pares, com a professora nas salas de aula e no pátio.

A entrevista foi direcionada às mães das crianças amostradas. O roteiro da entrevista cobriu 27 questões envolvendo aspectos relativos a: (1) cuidados iniciais à criança; (2) situação da moradia: espaços disponíveis e objetos físicos e sociais presentes; e (3) brincadeiras e lazer na casa e vizinhança; agentes de cuidados e interações com adultos. Alguns dados foram incluídos à entrevista, como: estado ci- vil e profissão dos pais, níveis educacional e econômico, gastos da família, seus hábitos e formas de organização.

\section{Procedimento}

Como a natureza da pesquisa referiu-se à descrição das relações interpessoais da criança nos contextos familiar e préescolar, a observação foi o primeiro instrumento a ser utilizado. Para o desenvolvimento desta atividade, estabeleceu-se um quadro indicativo dos dias e horários de observação nas classes e períodos das crianças amostradas. Os registros referentes às observações foram efetuados em uma ficha diária (protocolo de observação), envolvendo os seguintes itens: (1) Nome do observador; (2) objetivo da observação; (3) data da observação; (4) horário da observação; (5) diagrama da situação; (6) relato do ambiente físico; (7) descrição do participante observado; (8) relato do ambiente social; (9) técnica de registro utilizada e (10) registro propriamente dito.

O questionário foi direcionado às professoras, após o período destinado à observação e constituiu-se de itens referentes ao relacionamento interpessoal da criança (com seus pares e com a professora); participação nas atividades escolares, obediência às regras, comportamentos pró-sociais e anti-sociais da criança. As professoras responderam ao questionário fora do horário escolar, com base em orientações prévias e garantias de confidencialidade das informações obtidas.

A entrevista dirigida às mães envolveu itens relacionados às crianças, suas atividades, enfim seu contexto familiar. Os relatos das entrevistadas foram gravados, garantindo a tranqüilidade para ouvi-las e, ao mesmo tempo, eliminar o desconforto e os atropelos das anotações. O volume significativo de dados exigiu um longo período de leituras. Repetidas vezes foram ouvidos os conteúdos disponíveis e transcritos posteriormente. Finalmente, elaborou-se um conjunto de categorias referentes à vida familiar de cada participante da pesquisa.

\section{Resultados e discussão}

\section{Da observação e do questionário no contexto pré- escolar}

Durante todo o tempo de observação das atividades das crianças em classe, chamou a atenção o fato de que as professoras despendiam grande parte do tempo tentando acalmar ou repreender seus alunos, na tentativa de mantê-los em atividade. Em contrapartida, dias calmos, tranqüilos foram percebidos com surpresa: brincadeiras como trocas de lanches e objetos, conversas, resultavam em muitas risadas. Nesses dias de grande calmaria, professoras e observadora puderam perceber que os alunos briguentos e/ou provocadores não estavam presentes.

Observou-se também que as professoras revelavam falta de habilidades em administrar os momentos belicosos surgidos na sala de aula como agressões verbal e física entre as crianças. A preocupação fundamental resumia-se em ensinar conteúdos. Os intercâmbios entre professoras e mães baseavam-se em alguns pontos considerados prioritários como: 
problemas relacionados aos comportamentos indesejáveis como brigas e agressões e, sobretudo, o aproveitamento acadêmico. Os alunos quietos, tímidos, chorões ou emburrados não eram encarados como problemas. As brigas e disputas infantis presentes no contexto pré-escolar podem transformar-se em oportunidades para o desenvolvimento afetivo dos escolares. Crianças que brigam aprendem mais sobre raiva e agressão, se algo a mais for feito além de separá-las. Assim, professores e pais deverão conversar com as crianças para que elas relatem o conflito ocorrido e possam avaliar suas contribuições pessoais para a sua origem e desenvolvimento. Fazendo isso, estarão contribuindo para que as crianças adquiram habilidades em desenvolver relacionamentos e entendimentos emocionais positivos. Desse modo, professores e pais podem auxiliar as crianças a lidarem com seus sentimentos, em vez de simplesmente reprimi-los. À pré-escola cabe auxiliar as famílias a reforçarem determinadas práticas educativas e fazê-las conscientes dos problemas implicados em outro tipo de práticas educativas. Neste ponto, convém que se coloque uma ressalva: a tentação em estereotipar ou preconceituar os comportamentos já existentes, suas crenças ou idéias sobre educação e o cuidado a ser dispensado à criança, levam fatalmente ao enfrentamento e à descontinuidade entre as ações da família e da pré-escola. É necessário que a família e a escola mantenham canais de comunicação e relações de confiança mútua e compreensão (Vila, 2000). Quando os adultos, pais e professores trabalham juntos para os cuidados com as crianças, além de alimentarem o desenvolvimento delas, também enaltecem suas próprias vidas e contribuem com a valorização da comunidade (New, 2002).

\section{Da entrevista: no contexto familiar}

Observou-se que metade da amostra relacionava-se bem com seus pais. Grande parte dessas crianças, em contrapartida, apresentava um relacionamento belicoso com os irmãos, baseado em ciúme e rivalidade. Os comportamentos birrentos, agressivos e de desobediência eram crônicos. A maioria dos pais batia em seus filhos quando estes "faziam artes”. Existe uma grande diferença entre adquirir disciplina por identificação com aqueles a quem se admira e ganhá-la por imposição autoritária. As conversas entre pais e filhos eram relacionadas com avisos e expectativas de bons comportamentos. Tanto os elogios como os carinhos dispensados aos filhos eram rápidos e formais como beijos de boa noite, despedida ou de boas-vindas quando eles se dirigiam para a escola ou voltavam para casa. Uma característica que merece atenção referiu-se ao fato de que as mães pesquisadas garantiram a existência de regras, nem sempre obedecidas, razão dos pais baterem recorrentemente nos filhos. Gottman (1997) discute a existência de regras propostas pelos pais e a obediência a eles por parte dos filhos. Alguns pais são muito claros e consistentes, enquanto outros se perdem em discussões ou são vagos em relação ao que é esperado ou tolerado. Com base em Hart (1992), as crianças necessitam de limites seguros, saudáveis e razoáveis. Esses cuidados revelam amor. Os filhos sentem-se amados quando são orientados pelos pais naquilo que devem fazer ou não. Observou-se que essas mães eram dominadas por uma preocupação centrada no comportamento de suas crianças em casa e na escola. Essas características do comportamento de apego, dominantes nas famílias pesquisadas, referem-se ao segundo modelo citado por Bowlby. Trata-se do apego resistente ou ansioso, ou seja, a criança sente-se insegura por não ter a certeza de receber ajuda ou proteção dos pais, uma vez que estes podem estar indisponíveis em algumas ocasiões. É verdade que os pais de hoje enfrentam problemas que os do passado não enfrentavam e a maioria das mães deste estudo era de profissionais que atuavam fora de casa durante o dia. E isso pode indicar que os pais, ausentes devido ao trabalho, não ofereciam disponibilidade e paciência para ouvirem os filhos desabafarem seus problemas e conflitos. É na família que a criança encontra segurança, observa Winnicott (1997). Os pais fazem duas coisas ao mesmo tempo: protegem a criança do inesperado e seus próprios impulsos e de seus efeitos. A segurança lhe permite vivenciar o desafio que a convida a ser livre. As crianças pré-escolares cuja segurança do apego é elevada, lembra Gosselin (2000), complementando as idéias de Bolwby (1989), são atendidas não só em suas necessidades afetivas mas também em suas necessidades cognitivas. Assim, a tarefa de proteção não significa apenas o fornecimento de um contexto adequado (alimento, abrigo, afeto); estende-se também à tarefa de ensinar a criança os comportamentos valorizados pela sociedade que facilitarão sua adaptação à via acadêmica e social. Acrescenta-se, também, que as crianças seguras tendem a ser mais autônomas, mais capazes de desenvolver relacionamentos estáveis com seus pares; exibem menos tendência a terem problemas e, no caso de tê-los, revelarão maior persistência em resolvê-los (Rothbaum et al., 2000). As crianças seguras desenvolvem a compreensão do ambiente social e o papel que nele desempenham (Ramires, 2003).

Ficou evidenciado que grande parte das mães investigadas revelou-se exausta quando voltavam para casa após o trabalho. E o que encontravam em casa não tinha nada de animador. Além das tarefas domésticas a serem realizadas ou completadas, era necessário verificar os trabalhos escolares dos filhos, separar brigas. Não sobrava tempo para um relacionamento de qualidade, como conversar, ouvir as queixas das crianças ou mesmo participar de seus momentos de alegria. Mesmo aos domingos, as mães não conseguiam estar disponíveis para os filhos. O que gera problemas na educação das crianças não é o fato de os pais estarem o dia todo fora de casa em razão do trabalho, mas a maneira como se comprometem com a educação delas, a forma como administram seu tempo e o tipo efetivo de educação que colocam em prática. Existem outros fatores que apresentam efeitos muito mais danosos sobre a educação infantil do que o distanciamento dos pais todos os dias. Alguns exemplos são: distanciamento afetivo dos pais e filhos, disciplina severa e/ ou inconsistente, agressividade e falta de atenção aos filhos. O presente trabalho revelou que as crianças participantes assistiam aos programas na TV, desde desenhos, novelas, filmes, luta livre e outros programas para adultos. Se as crianças estão preferindo acomodar-se frente à TV como espectadores da vida retratada por scripts, a participarem da vida real 
através de relacionamentos interpessoais concretos, as conversas perderam seu lugar central na família. Desde que a televisão invadiu o tempo das pessoas e estas passaram a sentar-se passivamente e a ignorar umas às outras, os padrões de comunicação mudaram radicalmente e as conversas passaram a ser acontecimentos raros. O papel da televisão na vida das crianças tem sido mostrado, na maior parte das pesquisas, através de seus efeitos diretos, como a modelação de comportamentos violentos. É preciso que se leve em conta que seu perigo principal reside no impedimento de outros comportamentos como conversas, atividades esportivas, reuniões familiares, através das quais grande parte da aprendizagem da criança se desenvolve.

É preciso também salientar que a natureza positiva dos relacionamentos familiares não se mede pela quantidade de tempo disponível para esses intercâmbios, mas antes de tudo pela qualidade com que eles se desenvolvem na família. A solidariedade e a cooperação no cotidiano familiar não eram levadas em consideração, visto que a participação dos filhos nos trabalhos de casa não acontecia. De acordo com Zamberlan e Biasoli-Alves (1997), os pais participantes transformam seus lares em um ambiente em que todos cooperam nas tarefas domésticas. Os filhos sentem-se responsabilizados em realizar a sua parte e com isso aceitam a disciplina originada dessa divisão de trabalho, criando condições para a internalização de valores morais e conciliando-os com necessidades próprias de forma equilibrada. Esses aspectos dinâmicos gerados no ambiente familiar são considerados poderosos na vida da criança. É no lar que a criança desenvolve quase todos os repertórios básicos de seu comportamento, facilitando seus relacionamentos interpessoais no futuro. As crianças que auxiliam suas mães nas atividades domésticas poderão sentir-se úteis e indispensáveis no conjunto familiar. Sentimentos solidários e responsáveis ocuparão o lugar da disciplina rígida, em que os pais mandam, ordenam, e a criança deve obedecer, ou o lugar da disciplina permissiva, em que a criança faz o que deseja e por essa razão, sentir-se-á perdida pela ausência de limites. Dependendo da idade, a criança pode ser envolvida em auxiliar nas atividades como o preparo do jantar, arrumar a mesa, lavar e guardar a louça e utensílios, regar o jardim, arrumar as camas, etc.

O importante é que a atividade seja realizada em conjunto com a mãe e/ou o pai, propiciando situações de fazer junto. Além de viabilizar a conversa entre pais e filhos enquanto trabalham, esse tipo de situação contribui para o ensino de comportamentos de solidariedade e responsabilidade, podendo também auxiliar na produção de auto-estima elevada na criança ao possibilitar que ela se sinta útil.

As interações afetivas entre pais e filhos, conforme Gottman (1997), são de extrema importância. Quando as crianças se sentem seguras do afeto e do apoio dos pais, acredita-se que estarão mais protegidas contra as ameaças dos males atuais como violência, comportamento anti-social, vício de drogas, suicídio, etc.

Ao relacionar os comportamentos dos participantes deste trabalho na escola, ficou evidente que as crianças deveriam ficar em silêncio e sentadas em seus lugares. Entretanto, é difícil segurá-las em momentos de agitação. As professoras encaravam esse fato como prejudicial à aprendizagem, atividade de conhecimento. As mães, por sua vez, concordavam com essa visão, pois castigavam seus filhos quando eram chamadas à escola para ouvirem reclamações a respeito de seus comportamentos. Nos momentos mais tensos, caracterizados por brigas corporais, as professoras separavam as crianças dizendo que era feio brigar e esse fato era comunicado às mães. Como esses eventos eram crônicos, professoras e mães não conseguiam apresentar alternativas de solução de problema. Tampouco as crianças tímidas ou choronas eram encaradas como motivo de preocupação por ambas. As professoras acreditavam que suas responsabilidades resumiamse em desenvolver habilidades cognitivas; por essa razão não estavam preparadas para administrar problemas de caráter afetivo em sala de aula. Há indicadores de que mães e professoras desconheciam que a afetividade evolui, isto é, à medida que as crianças se desenvolvem cognitivamente, tornam-se mais exigentes em relação às necessidades afetivas. Por conseguinte, transmitir afeição, amor, inclui não apenas as ações de abraçar ou beijar, mas também conhecer, ouvir, conversar, admirar a criança pelos desempenhos. Não se verificou, no período de duração das observações, que as professoras conversassem com as crianças a respeito de seus trabalhos escolares. Em folhas de papel em que os trabalhos eram registrados havia marcas comuns a todas elas: "Está lindo!”, “ótimo”, “legal”, etc. É interessante registrar que algumas crianças, em especial algumas meninas, gostavam de conversar nos momentos do recreio e só encerravam essas conversas quando o sinal anunciava a volta às aulas. Era evidente a expressão de prazer nas fisionomias das meninas enquanto se comunicavam. Perceber essas cenas e tentar leválas para a classe poderia transformar a dinâmica de sala de aula, centrada em atividades cognitivas, em intercâmbios agradáveis em que crianças e professoras falassem sobre seus sentimentos e trocassem idéias. A falta de habilidade em administrar imprevisíveis crises emocionais (raiva, agressões verbal e física) pode provocar em pais e professoras desgaste físico e psicológico. Nos depoimentos das mães investigadas, ficou evidenciado que o castigo físico era aplicado sob o efeito da raiva, e que as mães justificavam seu uso porque "perdiam a cabeça” ou "as tiravam do sério”. Em salas de aula observouse repetidas vezes que as crianças que não obedeciam à professora, ou não realizavam tarefas, eram colocadas de castigo em um canto da sala "para pensarem”. Como esses fatos ocorriam com freqüência, é fácil supor que tais tentativas de solução de problemas não surtiam os efeitos esperados, tanto por parte das mães como das professoras.

\section{Considerações finais}

Com respeito aos dados gerais obtidos no presente trabalho, foi possível levantar implicações educacionais e aspectos susceptíveis de serem avaliados como sugestões aos pais e professoras de crianças pré-escolares. Trata-se do estudo dos aspectos considerados atualmente como indispensáveis ao desenvolvimento da criança. 
As duas últimas décadas têm mostrado que as famílias estão vivendo um mal-estar generalizado. Os anos iniciais do novo milênio revelam que as famílias refletem os problemas dos contextos mais amplos nos quais os seus membros vivem. Muitas se encontram contaminadas pelo estresse causado pelas mudanças econômicas e sociais. As mudanças na concepção sobre a importância e influência dos primeiros anos de vida para o desenvolvimento ulterior e a conquista de direitos da mulher e da criança têm produzido profundas transformações na estrutura familiar e no papel de cada um de seus membros.

Em geral, as crianças revelam-se atualmente mais nervosas, irritadas, mal-humoradas, deprimidas, solitárias, impulsivas e desobedientes (Goleman, 1995). Houve uma profunda mudança na visão da família nestes últimos anos. A maioria dos pais precisa trabalhar mais do que nas gerações passadas para sustentar a família, o que representa menos tempo de convívio com os filhos. As crianças permanecem em casa, sob cuidados de outras pessoas ou passando grande parte do tempo diante de uma tela de vídeo. Seja assistindo à televisão, seja monitorando um videogame, observam-se indicadores significativos de que elas não estão relacionando-se com outras crianças, tampouco recebendo atenção dos pais. A maioria dos pais, em tempos passados, concentrava-se tão somente em vencer as dificuldades inerentes a assegurar a seus filhos a sobrevivência e o bem-estar físico, sem considerar o desenvolvimento psicológico. Entretanto, nos dias de hoje, os pais precisam, além da sobrevivência, enfatizar a importância dos laços afetivos como base segura para a vida em família e alimentá-los tão seriamente quanto possível. Parece vir aumentando, nestas últimas décadas, o número de famílias com problemas para educar suas crianças. As reclamações mais freqüentes que os pais apresentam em relação à educação de seus filhos incluem as dificuldades em estabelecer limites ao comportamento infantil, enfrentar rebeldia e desobediência crônicas. Neste sentido, o objetivo principal do presente trabalho referiu-se à análise dos relacionamentos afetivos da criança na família e na pré-escola por ser um tema de atualidade e de grande interesse para pais e educadores.

\section{Referências}

Bee, H. (1996). A criança em desenvolvimento ( $7^{\underline{a}}$ ed.). Porto Alegre: Artes Médicas. Bowlby, J. (1989). Uma base segura: aplicações, clínica da teoria do apego. Porto Alegre: Artes Médicas.

Caballo, V. E. (2001) El papel de las habilidades sociales en el desarrollo de las relaciones interpersonales. In D. R. Zamignani (Org.), Sobre comportamen- to e cognição. A aplicação da análise do comportamento e da terapia cognitiva-comportamental no hospital geral e nos transtornos psiquiátricos (vol. 3, pp. 233-237). São Paulo: ESETEC - Editores Associados.

Edwards, C., Gandini, L., \& Forman, G. (1999). As cem linguagens da criança. A abordagem de Reggio Emília na educação da primeira infância. Porto Alegre: Artes Médicas.

Gandini, L., \& Edwards, C. (2002). Bambini: a abordagem italiana à educação infantil. Porto Alegre: Artes Médicas.

Goleman, D. (1995). Inteligência emocional, a teoria revolucionária que redefine o que é ser inteligente. Rio de Janeiro: Objetiva.

Gosselin, C. (2000). Fonction des comportements parentaux: révision de la notion de sensibilité maternelle. Psicologia: Teoria e Pesquisa, 6(2), 103-111.

Gottman, J. C., \& DeClaire, J. (1997). Inteligência emocional e a arte de educar nossos filhos ( $8^{\mathrm{a}}$ ed.). Rio de Janeiro: Objetiva.

Hart, L. (1992). A família moderna: uma reflexão sobre o desenvolvimento de uma relação madura e saudável entre pais e filhos. São Paulo: Saraiva.

Lohr, S. S. (2001). Desenvolvimento das habilidades sociais como forma de prevenção. In H. J. Guilhardi, M. B. B. P. Madi, P. P. Queiroz, \& M. C. Scoz (Orgs.), Sobre comportamento e cognição - expondo a variabilidade (Vol. 8, pp. 190-194). São Paulo: ESETEC - Editores Associados.

Lubi, A. P. L. (2003). Estilo parental e comportamento socialmente habilidoso da criança com pares. In M. Z. S Brandão, F. C. S Conte, F. S. Brandão, J. K. Inglerman, C. B. Moura, V. M. Silva, \& S. M Oliane (Orgs.), Sobre comportamento e cognição. a história e os avanços, a seleção por conseqüências em ação (Vol. 11, pp. 536-541). São Paulo: ESETEC - Editores Associados.

New, R. (2002) Quando c’è Figli (Quando se tem filhos): observações sobre a primeira infância na Itália. In L. Gandini, \& C. Edwards (Orgs.), Bambini: a abordagem italiana à educação infantil (pp. 229-245). Porto Alegre: Artes Médicas.

Ramires, V. R. R. (2003). Cognição social e teoria do apego: possíveis articulações. Psicologia, Reflexão e Crítica, 16(2), 403-410.

Rossetti-Ferreira. M. C. (1986). Mãe e criança. Separação e reencontro. São Paulo: Edicom.

Rothbaum, F., Weisz, J., Pott, M., Miyake, K., \& Morelli, G. (2000) Attachment and culture-security in the United States and Japan. American Psychologist, 55(10), 1093-1104.

Saldaña, M. R. R., Del Prette, A., \& Del Prette, A. A. P. (2003). A importância da teoria da aprendizagem social na constituição da área de treinamento de habilidades sociais. In H. J. Guilhardi, M. B. B. N. Madi, P. P Queiroz, \& M. C. Scoz (Orgs.), Sobre comportamento e cognição - contribuições para a construção da teoria do comportamento (Vol. 6, pp. 269-283). São Paulo: ESETEC - Editores Associados.

Vila, I. (2000). Aproximación a la educación infantil: características e implicaciones educativas. Revista Ibero-Americana, 22, 41-60.

Winnicott, D. W. (1997). A família e o desenvolvimento individual. São Paulo: Martins Fontes.

Zamberlan, M. A. T. (2002). Interação mãe-criança: enfoques teóricos e implicações decorrentes de estudos empíricos. Estudos de Psicologia, 7(2), 399-406.

Zamberlan, M. A. T, \& Biasoli-Alves, A. M. M. (1997). Interações familiares - teoria, pesquisa e subsídios à intervenção. Londrina: Editora da Universidade Estadual de Londrina.

Elza Maria Canhetti Mondin, doutoranda em Educação na Universidade Estadual Paulista-Marília, é professora na Faculdade de Filosofia, Ciências e Letras de Presidente Venceslau. Endereço para correspondência: Rua Maria Barbosa, 156; Presidente Venceslau, SP; CEP 19400-000. Tel: (18) 271-2262 ou 9771-6582. E-mail: elzamondin@hotmail.com 